\title{
The Usage of Bloom's Taxonomy in Teaching Chinese Phonetics to the Speakers of Other Languages
}

\author{
T. Pereloma \\ Taras Shevchenko National University of Kyiv \\ Corresponding author. E-mail: tanya199409@gmail.com
}

Paper received 23.06.19; Accepted for publication 14.08.19.

\section{https://doi.org/10.31174/SEND-PP2019-201VII81-07}

\begin{abstract}
Nowadays learning Chinese becomes more and more popular around the world. Such a trend provokes the growth of students, teachers and revising of already existed teaching theories and teaching methods. The following article is dedicated to the usage of Bloom's taxonomy as a tool of teaching Chinese phonetics to the speakers of other languages. It practically shows how worldwide known taxonomy can be applied to teach foreign language in the aspect of Phonetics.
\end{abstract}

Keywords: Bloom's taxonomy, chinese, chinese phonetics, methodology of teaching.

Nowadays learning Chinese becomes more popular everyday. According to the recent statistic there are 1.3 billion people speaking Chinese as a native language. On the second place is Spanish, with only 442 millions speakers compare to Chinese. Such a huge number of speakers leads to increasing a number of students who wish to learn Chinese and use it not only for their own purpose but also in work and study fields. [1]

The original Bloom's taxonomy was published in 1956 and revised by Anderson and Krathwohl, and as a result published in 2001. The Bloom's taxonomy proposed the following six levels of learning which can be used to build the learning objectives and lessons structure:
1) Remembering;
2) Understanding:
3) Applying:
4) Analyzing;
5) Evaluating;
6) Creating. [2]

We can apply every level of learning to the teaching of Chinese Phonetics on a course level.

Remembering. This stage Improves the student's ability to define terms, identify facts, and recall and locate information. It regards to recognizing, and recalling relevant knowledge from long-term memory. Talking about teaching Chinese it would be the best to highlight the learning of initials, finals and tones in Chinese. From the very beginning of studying process students have to obtain a strong base of understanding what tone in Chinese is and how to pronounce it with each and every sound correctly. The pronunciation of Chinese sounds in combination with tones has a crucial meaning on expressing what speaker wants to say and how it will be understood by the person to whom it may concern. The phenomenon of tones and pronunciation of Chinese sounds are the main things which differentiate Chinese phonetic from phonetics of other languages and play the key role in language system.

Understanding. Helps students connect new learning to prior knowledge. The overall «introduction» to the main aspects of Chinese phonetic by teacher (stage of remembering) must be followed by real examples which can help students to understand how these theoretical principles are used in reality. A teacher can use different audio and video sources recorded by native speakers to show students the main difference between four existing tones and pronunciation of different syllables. The usage of real examples on theoretical base form deeper understanding of Chinese phonetic peculiarities and it's realization in speech. It is also possible to compare syllables which available in Chinese to syllables in student's native language, such a contrast will lead to better understanding of material and its usage in future. Stage of understanding also can include live discussions and explanation of material learnt by students using their own words. On this stage teacher is able to see clearly the level of students knowledge and help them to fill available gaps if needed. This stage also may include an individual work regarding theoretical basics of Chinese phonetic which can be followed by in-class tests or visual presentations prepared by students according to their own investigations.

Applying. Provides opportunities to implement learned procedures and methods. After formation of foundational theoretical knowledge students have to try it by themselves. This stage directly connected with remembering and understanding as it combines the pronunciation of tones and syllables which they have learnt previously. As we are talking about phonetic, it is important to concentrate on syllables pronunciation with exact tone, not on the word meaning. It takes a long way for students to practice every syllable but it is an integral part of studying, It is important not to jump into the next stage of learning quickly, as the lack of practice in the initial level of language training can easily lead to bigger mistakes in the higher level of language competence. The following exercises on this level can be used:

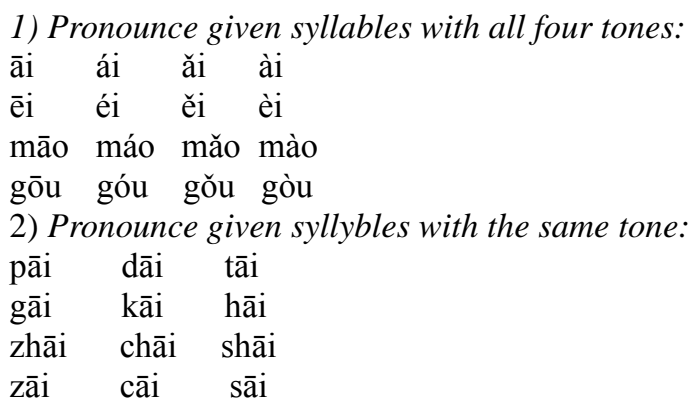

3) Listen to the given syllables and mark the one with the second tone:

$\begin{array}{llll}\text { māi } & \text { bái } & \text { tǎi } & \text { nài } \\ \text { fēi } & \text { béi } & \text { lěi } & \text { lèi } \\ \text { māo } & \text { máo } & \text { măo } & \text { mào } \\ \text { gōu } & \text { lóu } & \text { gǒu } & \text { lòu }\end{array}$


Analyzing. This stage regards to breaking material into constituent parts. After intensive practice students can analyze by themselves which syllables are easier to pronounce and which are more complicated. Same regards to the tones which are used together with all syllables accordingly. At this level students can be asked to build their own chart of «difficulties» where they can put all initials and finals from easiest to the most difficult one. Such a practical task make students to analyze all material which they have learnt till that moment and systemise it according to their own abilities. For example:

\begin{tabular}{|l|l|}
\hline $\begin{array}{l}\text { The most difficult } \\
\text { sounds }\end{array}$ & $\begin{array}{l}\mathrm{p}, \mathrm{t}, \mathrm{k}, \mathrm{j}, \mathrm{q}, \mathrm{x}, \mathrm{r}, \mathrm{z}, \mathrm{c}, \mathrm{y}, \mathrm{ang}, \text { iang, iao, } \\
\text { iong, iou, uang, er }\end{array}$ \\
\hline $\begin{array}{l}\text { Sounds with some } \\
\text { difficulties }\end{array}$ & $\begin{array}{l}\text { f, g, zh, ch, w, an, ian, in, ing, uai, uan, } \\
\text { uei, uen, ueng, en, eng, ong, ū, ūe, ūan, } \\
\overline{\mathrm{u} n}\end{array}$ \\
\hline $\begin{array}{l}\text { Sounds which are easy } \\
\text { to pronounce }\end{array}$ & $\begin{array}{l}\mathrm{b}, \mathrm{m}, \mathrm{n}, \mathrm{l}, \mathrm{s}, \mathrm{a}, \mathrm{ai}, \mathrm{ao}, \mathrm{i}, \mathrm{ia}, \mathrm{ie}, \mathrm{u}, \mathrm{ua}, \mathrm{uo}, \\
\mathrm{e}, \mathrm{ei}, \mathrm{o}, \mathrm{ou},\end{array}$ \\
\hline
\end{tabular}
Table 1.

This chart shows how student can possibly differentiate initials and finals according to his own abilities to pronounce, moreover it can help students to analyze their own mistakes and understand which sounds should be practiced «to clear» the chart with most difficult sounds. The ability to analyze not only helps students to classify sounds but also to make associations between Chinese and native language. Associations are always helpful for students and teachers in studying process. But it is also very important that native language should not interfere the language student learn

Evaluating. Evaluating regards to making judgments based on criteria and standards through checking. After formation of basic knowledge about what Chinese phonetic is, understanding what tone is and how it can be used, applying existing knowledge on practicing and analyzing of learnt material student can earn an ability to evaluate his own progress and progress of his peers. The stage of evaluation can contain self-evaluation during doing homework and drill exercises, and evaluation of your group mates during group-work and different assignments in and out of the classroom. The following questionnaire can be used by teacher to help students evaluate themselves after class-based tests:

\begin{tabular}{|l|l|}
\hline Question & Answer \\
\hline $\begin{array}{l}\text { How many mistakes you did you do in the } \\
\text { first test? }\end{array}$ & $*$ \\
\hline $\begin{array}{l}\text { Evaluate your score accordingly } \\
\text { (Excellent, good, satisfied, not satisfied) }\end{array}$ & $*$ \\
\hline $\begin{array}{l}\text { How many mistakes you did you do in the } \\
\text { second test? }\end{array}$ & $*$ \\
\hline $\begin{array}{l}\text { Evaluate your score accordingly } \\
\text { (Excellent, good, satisfied, not satisfied) }\end{array}$ & $*$ \\
\hline $\begin{array}{l}\text { Can your mistakes influence on your } \\
\text { communication with native speakers? }\end{array}$ & $*$ \\
\hline Are you satisfied with your score? & $*$ \\
\hline What have you practice more? & $*$ \\
\hline What is the reason of your mistakes? & $*$ \\
\hline What can you do to improve yourself? & $*$ \\
\hline
\end{tabular}

\section{Table 2.}

Creating. Producing new elements using existing knowledge. Talking about the stage of creating we can also use such a verbs like design, formulate, build, invent, create, compose, generate, derive, modify and develop. On the last level of material learning students have to reach an ability to create different phonetic structures (words, phrases, sentences or dialogues) by their own correctly. Students got through all stages successfully and now can produce sounds according to phonetic standards of Chinese language. This stage must contain different exercises which make students to design material by themselves and use language in all possible aspects. For example:

Create sentences using following words:

跳舞 tiàowǔ

摄影 hèyı̌ng

仰天儿 liáotiānr

看书 kànshū

After analyzing all stages of learning Chinese phonetics according to Bloom's taxonomy we can propose the following learning process of learning Chinese phonetics:

1) Provide a theoretical base of Chinese sounds and tones;

2)Provide real examples to support theoretical base which was given earlier;

3) Practice of examples given in the 2nd stage by students themselves;

4) Analyzing of Chinese syllables by students and dividing it from the most difficult to easiest one in accordance to build suitable practice system of Chinese sounds;

5) Evaluation of own pronunciation and evaluation of groupmates;

6) Applying formed knowledge in real practice.

\section{REFERENCES}

[1] "U.S. classroom digital learning materials acquisition reasons 2016 | Statistic', Statista.com, 2016. [Online]. Available: https:// www.statista.com/statistics/658530/us-classroomdigital-learning-materials-acquisition-reasons/. [Accessed: 08-

[2] Using Bloom's Taxonomy to Write Effective Learning Objectives 2018.[Online].

https://tips.uark.edu/using-blooms-taxonomy/ Available: Apr- 2019]. 